\title{
A ESCRITA NA AFASIA: DA PERDA À RECONSTITUIÇÃO DA LINGUAGEM
}

\author{
Magda Wacemberg Pereira Lima CARVALHO ${ }^{1}$ \\ Nadia Pereira da Silva Gonçalves de AZEVEDO ${ }^{2}$
}

\begin{abstract}
Resumo: Considerando que na afasia o quadro sintomático de linguagem é marcado pela "insistência/persistência de uma diferença" (LIER-DE VITTO, 2006, p. 186, grifo da autora), este trabalho tem como objetivo compreender aspectos do percurso de reconstituição da escrita de um sujeito em estado de afasia, cuja linguagem foi gravemente perturbada. Diante desse propósito, constituímos um corpus de análise formado por seis textos escritos pelo sujeito em diferentes momentos de sua recuperação. Em vista disso, o aporte teórico deste trabalho advém fundamentalmente de estudiosos da Afasiologia, Neurolinguística, Aquisição e Patologias de Linguagem, dentre os quais estão Freud (1977 [1891], 2013 [1891]); Jakobson (2008 [1954]); Morato (2010, 2012); Santana (2002); Macedo (2005, 2010); Lemos (1992, 1998, 2002, 2006); Lier-De Vitto (2006); Arantes $(2006,2009)$ e Borges (2006). Os resultados revelaram que o movimento de (re) composição da escrita do sujeito em questão foi marcado pela interação com o outro (terapeuta e familiar) que, como portador do texto-discurso, conduziu o sujeito à escrita por meio de atividades que envolviam situações cotidianas, (re) inserindo-o, dessa maneira, no funcionamento da linguagem escrita.
\end{abstract}

Palavras-chave: Linguagem. Afasia. Escrita.

\section{Introdução}

Considerando a afirmação de Jakobson (2008 [1954], p. 34) de que "para estudar, de modo adequado, qualquer ruptura nas comunicações, devemos, primeiro, compreender a natureza e a estrutura do modo particular de comunicação que cessou de funcionar",

\footnotetext{
1 UNICAP - Universidade Católica de Pernambuco - Programa de Pós-graduação em Ciências da Linguagem. Recife - Pernambuco - Brasil. 52041-040 - magdapcarvalho@hotmail.com

${ }^{2}$ UNICAP - Universidade Católica de Pernambuco - Programa de Pós-graduação em Ciências da Linguagem. Recife - Pernambuco - Brasil.52041-040 - nadiaazevedo@gmail.com
} 
este trabalho tem como objetivo analisar aspectos do percurso de reconstituição da escrita de um sujeito, cuja linguagem foi severamente afetada devido a uma contusão hemorrágica córtico-subcortical, que comprometeu a região temporal esquerda de seu cérebro.

Diante desse propósito, nosso corpus de análise é composto por seis textos escritos $^{3}$ pelo sujeito em diferentes momentos de sua recuperação, que, em aproximadamente seis meses de tratamento, passou de uma escrita nonsense ${ }^{4}$ com a presença de traços incompreensíveis de letras para uma escrita clara, coesa e coerente.

Em vista disso, a hipótese que vislumbramos é a de que o sujeito em estado de afasia, cuja escrita foi gravemente perturbada, quando colocado em contato com atividades de escrita que consideram a língua em situações reais de comunicação, pode passar de uma escrita nonsense para a escrita de textos da língua constituída.

Com base nesse pressuposto, a posição teórica que assumimos é a do Interacionismo ${ }^{5}$, conforme proposto por Cláudia de Lemos (2002), no campo da Aquisição de Linguagem, em razão de que, no movimento de (re) composição da linguagem, a escrita do sujeito afásico se apresenta como um enigma, como algo que passa a interrogar o investigador, assim como a escrita da criança em fase de aquisição de linguagem, o que nos leva, seguindo Lemos, a compreender o sujeito como capturado pela linguagem e submetido ao seu funcionamento.

Contudo, como essa perspectiva teórica não apresenta esclarecimentos suficientes sobre a limitação inicial do gesto de escrita do afásico, buscamos no campo da Neurolinguística algumas questões já discutidas por Santana (2002) e Macedo (2005, 2010) sobre a escrita nos quadros afásicos.

Embora a perspectiva teórica assumida pela Neurolinguística seja a enunciativodiscursiva $^{6}$, tentaremos empreender diálogo entre esse campo e o Interacionismo em

\footnotetext{
${ }^{3}$ É importante ressaltar que o acesso a esses textos nos foi possível somente dois anos depois da recuperação do sujeito, em 2013, quando sua mãe apresentou-nos um dos cadernos de exercícios pertencente ao filho.

${ }^{4}$ Termo usado por Borges (2006, p. 150) para se referir às "combinatórias de letras que não constituem palavras da língua constituída", escritas pela criança em fase de aquisição de linguagem.

${ }^{5}$ Convém ressaltar que, embora a maioria das investigações realizadas com base na proposta formulada por Lemos tenha como fundamento o estudo da fala da criança em fase de aquisição de linguagem, essa teoria também tem oferecido subsídios para a investigação das patologias de linguagem, a partir da aproximação entre a Fonoaudiologia e a Linguística.

${ }^{6}$ A perspectiva enunciativo-discursiva parte da compreensão bakhtiniana de que todos os diversos campos da atividade humana estão ligados ao uso da linguagem, cujo "emprego da língua efetua-se em forma de enunciados (orais e escritos) concretos e únicos, proferidos pelos integrantes desse ou daquele campo da atividade humana" (BAKHTIN, 2003, p. 261) na produção de seus discursos.
} 
Aquisição de Linguagem por entendermos que "a Neurolinguística tem cada vez mais condições de dialogar não apenas com uma determinada concepção de língua e cognição, mas com as possibilidades que se abrem pelos vários domínios ou campos da Linguística" (MORATO, 2012, p. 196).

Antes disso, para entender a origem das pesquisas sobre afasia é necessário situála no plano dos estudos afasiológicos e linguísticos, o que apresentaremos a seguir.

\section{Algumas considerações sobre a Afasiologia}

A afasia, conforme Morato (2010, p. 12), “é como são denominados os problemas de linguagem - oral e/ou escrita - decorrentes de lesões cerebrais causadas especialmente por acidentes vasculares cerebrais (hemorrágicos ou isquêmicos), tumores ou traumatismos cranioencefálicos".

Nessa perspectiva, o que faz presença na afasia, de acordo com Vieira (2006, p. 235), é a relação biunívoca entre alterações de linguagem e a lesão no cérebro, dado que a definição da afasia como "perda da linguagem decorrente de lesão cerebral" (idem, grifo da autora) foi concebida pela Afasiologia - um dos campos da Medicina.

Os primeiros estudos sobre afasia, segundo Freud (2013 [1891]), foram realizados por pesquisadores da área de Neuropatologia como Wernicke, Bastian, Ross, Charcot, dentre outros. De acordo com Freud, as pesquisas sobre o tema apresentavam duas suposições para o fenômeno da afasia, a primeira

[...] tem como conteúdo a diferenciação das afasias provocadas por destruição dos centros corticais daquelas provocadas por destruição das vias de condução; [...]. A segunda suposição diz respeito à relação recíproca entre cada um dos centros corticais supostamente ligados às funções de linguagem [...] (FREUD, 2013 [1891], p. 17, grifo do autor).

Nessa linha, a alteração da atividade de linguagem foi considerada, inicialmente, como um evento de ordem neurológica, em que no aparelho de linguagem "separaram-se os distúrbios de linguagem em duas classes, as afasias, provocadas por lesão localizada, e as amnésias, provocadas por modificação funcional não localizada" (FREUD, 2013, p. 128). Dessa forma, a Afasiologia em seu início pode ser compreendida, consoante Morato 
(2012, p. 176), como o campo de estudo das correlações entre linguagem e determinadas áreas do cérebro que seriam por ela responsáveis.

Questionando a corrente localizacionista, que postulava a "área de Broca" (lobo frontal do hemisfério esquerdo) como a sede da linguagem no cérebro, Freud em seu texto “A interpretação das afasias" (1977 [1891]) destaca a necessidade de alterar a metodologia clássica, que inferia o normal a partir do patológico ${ }^{7}$, visto que entre $\mathrm{o}$ normal e o patológico havia, no entendimento desse autor, uma continuidade constitutiva, funcional e não uma ruptura de ordem orgânica, dado que "o aparelho da linguagem dispõe de uma tal riqueza de expressões sintomáticas que só dele podemos esperar a revelação, [...], não só da localização mas também da lesão" (FREUD, 1977, p. 41).

Em meados do século XX, estudiosos da Afasiologia admitiam, conforme Morato (2012, p. 179), que o cérebro operava obedecendo "a uma lei hierárquica de organização das funções mentais". Contudo, foi a partir da noção de "sistema funcional complexo", introduzida por Luria no campo da Neuropsicologia que a afasia passou a ser concebida "não apenas como um problema de articulação da fala, mas também como uma alteração do sistema linguístico como um todo (fala, audição, leitura e escrita)" (MORATO, 2012, p. 180).

Com isso, a afasia passou a ser vista como um problema de ordem metalinguística, trazendo à tona, conforme a autora, a relação do sujeito com a produção e a interpretação da linguagem.

Nesse cenário, o linguista russo Roman Jakobson, tentando construir uma teoria geral da linguagem que explicasse a aquisição, o funcionamento, a estrutura e a alteração da linguagem, "focalizou as afasias de um ponto de vista linguístico no contexto do estruturalismo e funcionalismo" (MORATO, 2012, p. 186), isso porque, em seu entendimento, as afasias dariam solidez empírica a sua teorização sobre o funcionamento da linguagem, conforme Morato (ibidem, p. 187), justamente por ferir a norma, a gramaticalidade, os padrões estruturais e funcionais da língua.

Diante disso, Jakobson trabalhou a partir da proposta saussuriana de relações sintagmáticas e relações associativas, postuladas por Ferdinand de Saussure no Curso de Linguística Geral (1916).

\footnotetext{
${ }^{7}$ O conceito de patologia é discutido por Georges Canguilhem, no livro O normal e o patológico (2009 [1966]). Para esse autor (idem, p. 64), "ser doente é, realmente, para o homem, viver uma vida diferente, mesmo no sentido biológico da palavra".
} 
No Curso, Saussure explica que as relações sintagmáticas existem in praesentia devido à presença de dois ou mais termos numa série efetiva enquanto as relações associativas ocorrem in absentia numa série mnemônica virtual. Nessa ordem, Jakobson (2008 [1954]) estabeleceu dois grandes eixos de relações (simbólicas), a saber, eixo metonímico/sintagmático - responsável pela combinação de unidades, e eixo metafórico/associativo - responsável pela seleção de unidades.

Para Jakobson (2008, p. 37), “quem fala seleciona palavras e as combina em frases, de acordo com o sistema sintático da língua que utiliza". Dessa maneira, o arranjo da seleção presume a substituição de termos entre si a partir de entidades associadas no sistema, enquanto o arranjo da combinação demanda certa articulação das unidades linguísticas associadas no sistema linguístico e na mensagem ou associadas somente na mensagem. Partindo dessa compreensão, Jakobson analisa os distúrbios da linguagem pela relação de similaridade (substituição) entre os signos e pela relação de contiguidade (combinação) entre os elementos lexicais.

Para os afásicos do primeiro grupo (similaridade ou seleção), o contexto de produção é decisivo, pois a palavra não ocorre de forma livre, mas de forma vinculada. Segundo Jakobson (2008), devido a uma deterioração da metalinguagem, o afásico desse grupo é incapaz de dizer uma palavra isoladamente. No caso dos afásicos do segundo grupo (contiguidade ou combinação), a palavra é uma entidade preservada, que aparece nas frases como um amontoado de termos em que não há regras sintáticas ou gramaticais.

Jakobson (2008, p. 36) explicita que "a pesquisa sobre a ordem das aquisições e das perdas e sobre as leis gerais de implicação não pode ser limitada ao sistema fonológico, mas deve estender-se também ao sistema gramatical", o que pressupõe o estudo de situações linguísticas produzidas também em contextos de escrita, não implicando dizer, aqui, que o estudo das produções escritas pelo sujeito afásico deva se reduzir à metalinguagem.

Nessa perspectiva, concordamos com Macedo (2005) que o trabalho com escrita na afasia deve ser considerado como uma espécie de ação reflexiva do sujeito sobre a linguagem em funcionamento, devendo-se, portanto, levar em consideração as práticas de letramento e as práticas interacionais do sujeito. 
Mediante esse entendimento, acreditamos que é possível estabelecer um diálogo entre a Neurolinguística e o Interacionismo em Aquisição de Linguagem, o que tentaremos fazer na próxima seção.

\section{Neurolinguística e Interacionismo em Aquisição da Linguagem: um diálogo possível}

Dentre as visões formuladas sobre a Neurolinguística, o conceito que apresenta uma concepção mais tradicional, de acordo com Morato (2012, p. 168), é o que define esse campo como "o estudo das relações entre cérebro e linguagem, com enfoque no campo das patologias cerebrais e na relação de determinadas estruturas do cérebro com distúrbios da linguagem".

Diante disso, um dos interesses da Neurolinguística é investigar como o cérebro reage ante as dificuldades linguísticas após o dano neurológico, o que coloca a Neurolinguística como um campo interdisciplinar "cujo foco é o estudo das relações entre linguagem, cérebro e cognição" (MORATO, 2012, p. 170), consequentemente, do processamento entre o normal e o patológico da linguagem, visto que os dados obtidos no contexto patológico, segundo Morato, concorrem para a compreensão dos processos normais em aquisição e desenvolvimento da linguagem e da cognição.

Assim, considerando a Neurolinguística como um campo interdisciplinar de estudo, compreendemos que é possível uma aproximação entre essa área e o Interacionismo em Aquisição de Linguagem como postulado pela brasileira Cláudia de Lemos, uma vez que ambas consideram a interação ${ }^{8}$ essencial à produção de linguagem.

Cabe destacar que os principais trabalhos de investigação acerca dos distúrbios de linguagem no Interacionismo estão voltados para as falas sintomáticas, que segundo LierDe Vitto (2006, p. 185) diferem do "erro" que aparece na fala inicial da criança ou na fala do adulto, seja por conta da resistência que impõe à mudança; seja pelo efeito distinto que produz na escuta do outro. Para essa autora, o sintoma é aquilo que leva o sujeito à clínica

\footnotetext{
${ }^{8}$ Salientamos que o termo "interação" assume diferentes matizes nas diversas abordagens linguísticas. No Construtivismo, formulado por Piaget, esse termo é usado para explicar a gênese e o desenvolvimento da linguagem na criança, pela interação com o ambiente; no Sociointeracionismo, de Vygotsky, o termo "interação" explica o desenvolvimento da linguagem com base na construção conjunta da linguagem e do diálogo, trata-se da comunicação entre os interlocutores; no Interacionismo em Aquisição de Linguagem, conforme a formulação de Lemos, trata-se da relação sujeito-língua; e em Bakhtin, o termo "interação" envolve os aspectos ideológico, dialógico e sócio-histórico, referindo-se à interação sócio-verbal.
} 
de linguagem devido ao "efeito" que a fala desviante produz tanto na escuta do ouvinte quanto na sua própria.

Segundo Lier-De Vitto (idem), o que demarca um quadro de desvio de linguagem é a insistência/persistência de uma diferença, de uma fala que resiste à mudança de posição na linguagem. Nessa ordem, a clínica de linguagem é convocada, de acordo com a autora, a incidir sobre o que é sintomático na fala do sujeito e que lhe faz sofrer. Diante dessa compreensão, Lier-De Vitto busca aproximar a Fonoaudiologia à Linguística, já que esta última, para a autora, produz um dizer sobre o sintoma na linguagem.

A partir desse entendimento, Lier-De Vitto (2006, p. 184) afirma que não é qualquer teoria Linguística que poderá dialogar com a Fonoaudiologia, e sim uma em que interação e outro sejam proposições problemáticas.

Nesse sentido, a proposta de Cláudia de Lemos, no campo da Aquisição da Linguagem, é exemplar porque remete, conforme Arantes (2006), ao modo singular de "captura" do ser pela linguagem, oferecendo condições para uma reflexão sobre o sujeito e sua fala sintomática, em razão de que Lemos estuda as relações do sujeito com a língua, evidenciando o outro-falante como sede do funcionamento da língua constituída.

Nessa ordem, embora compreendamos que o Interacionismo em Aquisição de Linguagem se apresenta como um movimento teórico possível para a compreensão do percurso de reconstituição da escrita na afasia, observamos que o estudo da escrita do afásico ainda é bastante limitado nessa área, o que nos mobiliza a lançar mão das discussões apresentadas pela perspectiva enunciativo-discursiva, sobretudo o que diz respeito à relação entre fala e escrita ou, nos termos de Macedo (2005), oralidade e letramento.

É importante esclarecer que a ideia de letramento adotada por essa autora é a "que o define como um conjunto de práticas de comunicação social relacionadas ao uso de materiais escritos" (MACEDO, 2005, p. 45). Nessa concepção, as práticas de letramento não correspondem ao nível de alfabetização dos sujeitos, mas ao conhecimento que o sujeito tem da língua e ao uso que faz dela em seu cotidiano.

Diante disso, considerando que nossa questão incide sobre a compreensão do percurso de reconstituição da escrita do afásico, convém observar que "aspectos como letramento, qualidade de vida, idade, diversos aspectos socioculturais e emocionais 
promovem diferentes manifestações clínicas em sujeitos que apresentam lesões em uma mesma região cerebral” (MACEDO, 2010, p. 218).

Nesse entendimento, é possível que os textos escritos pelo sujeito desta pesquisa apresentem resultados diferentes dos casos observados por Macedo em sua tese de doutoramento (2005), uma vez que o interesse dessa pesquisadora estava voltado para o trabalho de refacção dos textos escritos de sujeitos afásicos, enquanto a nossa atenção está direcionada para a semelhança que há entre o percurso de recuperação da escrita do afásico e o processo de aquisição da escrita da criança em fase de aquisição de linguagem.

Isso nos leva a compreender o Interacionismo como um movimento teórico possível de explicar o percurso de reconstituição da escrita na afasia, porque a proposta de Lemos, a partir da questão do "erro" em aquisição de linguagem, assinala um novo momento de teorização, cuja proposição integra concepções do outro e da relação do sujeito com a língua e com o próprio sujeito.

Diante desse entendimento, acreditamos que se faz necessária a apresentação de algumas considerações sobre a aquisição da escrita no Interacionismo e o trabalho com a linguagem escrita no campo da Neurolinguística, o que faremos a seguir.

\section{A escrita no interacionismo em aquisição de linguagem e a escrita na afasia}

Considerando que a proposta teórica formulada por Lemos no campo da aquisição de linguagem oferece elementos para o estudo da aquisição da escrita e das patologias da linguagem, assumimos a proposta de que "a imersão em textos promove ou é determinante do processo de aquisição da escrita" (BORGES, 2006, p. 149), o que implica a suposição de um sujeito alienado ao discurso do outro (semelhante) e do Outro9 .

Nessa perspectiva, o outro é tomado como representante do funcionamento da língua constituída, cujo papel seria "o de intérprete. [...] que se oferece ao mesmo tempo como semelhante e como diferente" (LEMOS, 1998, p. 19), em razão de que ler para a criança, interrogá-la sobre o sentido do que "escreveu" e escrever para que ela leia são

\footnotetext{
${ }^{9}$ O Outro para a psicanálise lacaniana corresponde ao "lugar em que se situa a cadeia do significante que comanda tudo que vai poder presentificar-se do sujeito, é o campo desse vivo onde o sujeito tem que aparecer" (LACAN, 2008 [1964], p. 200). Contudo, como não é nossa pretensão tratar aqui sobre questões psicanalíticas na escrita de sujeitos afásicos, optamos por não nos aprofundarmos nessa teoria.
} 
situações que, de acordo com a autora, contribuem para a inserção da criança no movimento linguístico-discursivo da escrita.

Segundo essa concepção, o texto escrito pode entrar em relação com o texto oral, ganhando uma significação que vem a ser interpretada como referência a ele. De acordo com Lemos, esse processo de ressignificação "incidiria fundamentalmente sobre cadeias de textos-discursos, e não sobre unidades como palavras e sílabas, letras e fonemas" (LEMOS, 1998, p. 19), o que nos encaminha à hipótese de Macedo de que, no contexto das afasias, o trabalho com escrita leva a uma reflexão e a uma discussão sobre as relações entre oralidade e escrita que por serem variadas e múltiplas "constituem atividades significativas para cada um dos sujeitos que têm sua linguagem afetada" (MACEDO, 2005, p. 83).

Ainda sobre a aquisição de linguagem, Borges (2006) observa que quando colocada em situações de leitura e escrita que não priorizam a correspondência entre grafemas e fonemas, a criança escreve a partir de uma cadeia de significantes que, se analisada sob a ótica da proposta formulada por Lemos, "pode-se dizer que as características da escrita da criança decorrem de movimentos 'da linguagem sobre a linguagem' sobre os quais a criança não tem controle" (BORGES, 2006, p. 152). Isso ocorre porque o jogo de estruturas complexas ${ }^{10}$ que emergem na escrita inicial da criança pressupõe sua captura pela língua e sua inserção no movimento linguístico-discursivo.

É importante destacar que a questão da captura da criança pela língua foi discutida por Lemos no texto Das vicissitudes da fala da criança e de sua investigação (2002). Nesse trabalho, a autora afirma que a noção do projeto estruturalista, por considerar a língua como sistema de signos e de valores depositado nos cérebros dos indivíduos através da comunicação social, aponta para uma alteridade radical, o que, em seu entendimento, dá à língua a função de captura.

Para Lemos (2002, p. 55), a criança é capturada "por um funcionamento linguístico discursivo que não só a significa como lhe permite significar outra coisa para além do que ela significou". Nessa perspectiva, a autora apresenta uma proposição que integra concepções do outro e da relação do sujeito com a língua e com o próprio sujeito.

\footnotetext{
${ }^{10}$ Expressão empregada por Borges (2006, p. 151) para se referir à organização dos textos da criança acompanhada por ela durante a realização de sua pesquisa.
} 
Essa proposta consiste na possibilidade de mudança de posição em uma estrutura, cujos polos são o outro, a língua e o próprio sujeito, em que a primeira posição é marcada "pela dominância da fala do outro, na segunda posição, pela dominância do funcionamento da língua e, na terceira posição, pela dominância da relação do sujeito com sua própria fala" (LEMOS, 2002, p. 56). Com isso, a autora envolve a noção de língua como sistema, o que a faz recorrer à linguística estruturalista, sobretudo Saussure e Jakobson.

De acordo com Lier-De Vitto e Carvalho (2008, p. 135), a proposta saussuriana é invocada porque "oferece uma visão de linguagem compatível tanto com questões epistemológicas quanto com os argumentos empíricos do Interacionismo”, pois permite abordar la langue e seu funcionamento nas falas heterogêneas e imprevisíveis da criança.

Segundo Lemos (2002, p. 54), a presença das formulações saussurianas demanda a articulação de "um sujeito [...] compatível com a concepção de língua na teorização da Linguística". Trata-se de um sujeito que existe enquanto efeito de linguagem e cuja constituição se faz necessariamente em sua relação com o outro-falante por meio da linguagem. Diante disso, o sujeito é então entendido como "capturado" pela linguagem e submetido ao seu funcionamento.

No que diz respeito à afasia, Santana (2002, p. 16) afirma, com base nos estudos da Neurolinguística e da Neuropsicologia, que as atividades de escrita realizadas com os afásicos se configuram "não apenas dissociada[s] da linguagem oral, como também isolada[s] em sua própria configuração", uma vez que essas atividades consistem, conforme a autora, em cópia de letras, palavras e frases, ditado de palavras e leitura de textos curtos em voz alta. Isso equivale a dizer que "o afásico é avaliado exatamente como os alunos nos bancos escolares, por meio de tarefas fragmentadas" (SANTANA, 2002, p. $57)$.

Com isso, a avaliação a que os sujeitos afásicos são submetidos se reduz, de acordo com Santana (2002, p. 16), a "uma avaliação puramente psicofísiológica e cognitiva dos processos de leitura e de escrita". Macedo (2010) também observa que a maior parte das atividades de escrita a que os afásicos são submetidos tem uma preocupação essencialmente metalinguística, com exercícios de "soletração, ditado, cópia, evocação escrita, figuras para nomear e descrever, pareamento entre figuras, ações e palavras ou sentenças e textos a copiar e ditar" (MACEDO, 2010, p. 226), o que, em 
nosso entendimento, limita o potencial de escrita de qualquer sujeito, seja ele afásico ou não.

Segundo Santana (2002), o que se tem observado na Afasiologia como resultado da avaliação das produções linguísticas dos sujeitos é a concepção da afasia como problema meramente fonoarticulatório, que resulta, geralmente, em diagnóstico de apraxia e disartria. Isso ocorre, conforme a autora, devido à oralidade ocupar lugar privilegiado desde os primeiros estudos afasiológicos.

Com isso, presume-se que o trabalho de linguagem realizado com sujeitos vítimas de dano neurológico desconsidera a escrita como atividade linguístico-discursiva, tanto nos procedimentos avaliativos quanto no acompanhamento terapêutico, o que nos faz supor que a tradição afasiológica não tem levado em consideração que "a dificuldade linguística que se impõe ao paciente nos quadros afásicos se apresenta de forma tal que modifica a posição do sujeito em relação ao mundo, à vida - aparece como um vazio, um vazio que se traduz em sofrimento" (VIEIRA, 2006, p. 244).

Esse sofrimento faz com que o sujeito dirija para a clínica "uma demanda a um outro que é, por isso, investido da capacidade de produzir mudanças" (LIER-DE VITTO, 2006, p. 184, grifo da autora). Nessa ordem, esse "outro" se mostra como aquele capaz de ajudar o sujeito no processo de reconstituição da linguagem, independente de qual aspecto da linguagem foi prejudicado, em razão de que o outro, de acordo com Macedo (2005, p. 69), é um mediador que auxilia o afásico na retomada de um texto, na leitura e releitura de um texto próprio.

Mediante esse entendimento, Macedo (2005, p. 61) afirma que “os afásicos, mais do que outros escreventes, precisam da interlocução para proceder a qualquer reformulação em seus discursos, especialmente quando se trata de um texto escrito", pois nas atividades de linguagem a interação e a interlocução são fundamentais, principalmente quando se consideram as situações reais de uso da língua.

Nessa perspectiva, compreendemos que reduzir as atividades de escrita na afasia a ditados, cópias ou exercícios metalinguísticos acaba limitando e comprometendo o processo de reconstituição da escrita do afásico, pois o sujeito afásico, por estar "sem a possibilidade da linguagem - ler, escrever, falar e entender” (VIEIRA, 2006, p. 243), necessita, assim como a criança em fase de aquisição, ser conduzido pelo outro e submetido ao funcionamento da língua. 
Dessa forma, concordamos com Macedo (2005) que o trabalho com escrita na afasia deve considerar as diferentes histórias, as práticas de letramento e a interação para que a condição de sujeito-escrevente seja restabelecida.

\section{A pesquisa}

Partindo da compreensão de que oralidade e escrita são atos de linguagem, em que cada modalidade se dá por meio de processos linguístico-discursivos e de interação, constituímos um conjunto de seis textos escritos por um sujeito em estado afásico.

A afasia desse sujeito se deu em decorrência de um acidente automobilístico, em fevereiro de 2011, que resultou em traumatismo craniano encefálico, tendo o paciente ficado em estado de coma (profundo e induzido) por 56 dias.

Após 80 dias de internação, o sujeito, na época, com 26 anos recebeu alta hospitalar, mas com orientação médica para seguir tratamento de fisioterapia e fonoaudiologia, devido ao diagnóstico de disartria e afasia motora.

Convém destacar que o sujeito, graduado em Matemática, com especialização em Ensino de Matemática, mantinha uma rotina intensa de estudos, o que assegurou sua aprovação no concurso da Polícia Militar de Pernambuco, em 2009. Após ser aprovado, o sujeito continuou dedicado à rotina de leitura e escrita exigida pela Academia de Polícia Militar durante o curso de formação policial, interrompido quando sofreu o episódio neurológico.

Devido a uma contusão hemorrágica córtico-subcortical na região temporal esquerda do cérebro, a fala e a escrita do sujeito foram severamente prejudicadas, tendo permanecido apenas sua capacidade de compreensão. Diante desse quadro, depois de sair do estado de coma, o sujeito foi estimulado pelo terapeuta e por familiares (mãe e noiva), que o acompanhavam no hospital, a fazer exercícios diários de fala e escrita, esses últimos registrados em um caderno cujo conteúdo nos foi cedido pela mãe do sujeito, mediante assinatura de termo de consentimento para estudo do material.

A escrita dos textos foi iniciada logo após o sujeito recuperar a consciência, em abril de 2011. Nesse período, o sujeito segurava o lápis com dificuldade e embora não apresentasse coordenação motora adequada, escrevia o que, para ele, eram letras da língua constituída. 
Entre os meses de maio e junho (2011), o sujeito passou a apresentar uma escrita compreensível, o que pode ser entendido como indícios de preservação de seu letramento e, a partir dos meses de julho e agosto (2011), apresentava textos descritivo-narrativos sobre acontecimentos de seu cotidiano.

Foi a partir da evolução observada nos textos do sujeito que buscamos, no Interacionismo em Aquisição de Linguagem e na Neurolinguística, explicações sobre o percurso de reconstituição da escrita desse sujeito.

Nessa perspectiva, optou-se pela pesquisa qualitativa, visto que esse tipo de pesquisa "considera que há uma relação dinâmica entre o mundo real e o sujeito, isto é, um vínculo indissociável entre o mundo objetivo e a subjetividade do sujeito que não pode ser traduzido em números" (KAUARK et al., 2010, p. 26).

Quanto ao método de abordagem, decidiu-se pelo método indutivo, dado que a aplicabilidade dessa metodologia compreende, segundo Oliveira (2012, p. 50), “a observação e a experimentação dos fenômenos estudados", permitindo o entendimento de uma situação abrangente a partir da verificação de um objeto particular. Já no que diz respeito ao procedimento, optou-se pelo estudo de caso, visto que esse tipo de procedimento é, conforme Goode e Hatt (1979), um meio de organizar os dados, preservando do objeto estudado o seu caráter unitário.

Com base nesses pressupostos, o estudo será realizado a partir da delimitação da unidade-caso, da seleção e análise do corpus.

\section{Análise e discussão de textos de um sujeito afásico}

A partir de agora, passa-se a enfatizar o trabalho com a análise e discussão dos seis textos produzidos pelo sujeito afásico em estudo.

Vejamos esses textos: 


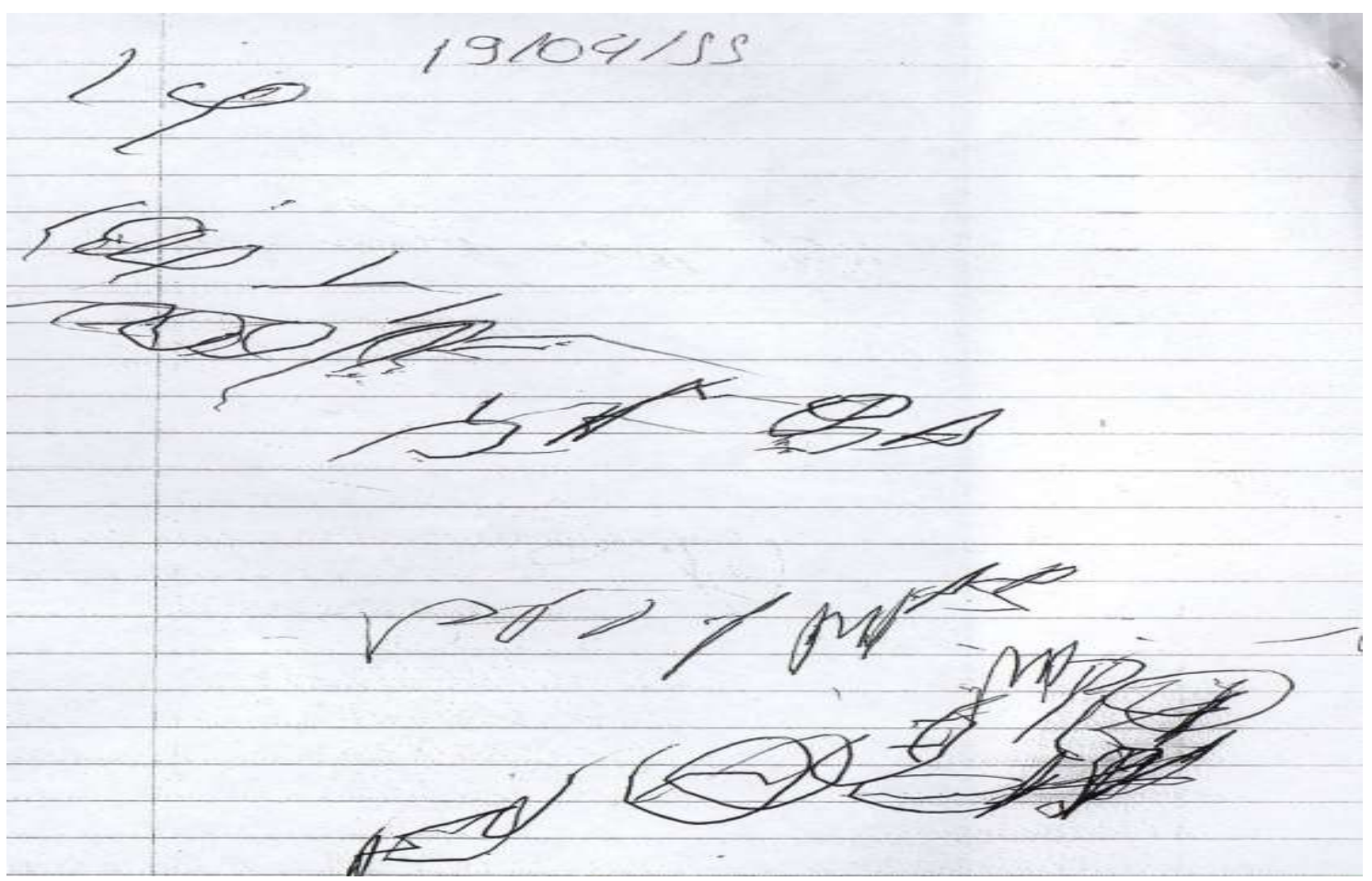

Texto 1: 19/04/2011

Escrito dois meses depois do acidente automobilístico, quando o sujeito ainda estava hospitalizado, esse texto remete-nos à escrita inicial da criança em fase de aquisição, que começa traçando hieróglifos ${ }^{11}$ antes de dar o passo que vai levá-la à escrita alfabética.

Solicitado pelo terapeuta a escrever seu nome completo, o sujeito iniciou o percurso de recomposição da escrita produzindo "rabiscos" de letras cujo traço, embora incompreensível para outros leitores, comportava significado para o sujeito, nesse caso sua assinatura.

Esse primeiro momento do processo de reconstituição da escrita do afásico nos encaminha para a fala de Borges (2006) sobre a escrita inicial da criança. Para essa autora, se olharmos para as produções escritas "mesmo as mais iniciais, vemos um jogo gráfico: combinatórias de letras que não constituem palavras da língua constituída, mas que têm sistematicidade mesmo que com efeito de nonsense" (BORGES, 2006, p. 150).

A sistematicidade a que Borges se refere pode ser observada pela disposição do traço de letras no papel em que as inscrições de letras, apesar de não se apresentarem retilineamente, aparecem organizadas lado a lado, levando-nos a compreender que, após

\footnotetext{
${ }^{11}$ Termo usado por Gérard Pommier no texto "A história da escrita e aprendizagem de cada criança" (2011).
} 
o episódio neurológico, o sujeito, em sua escrita inicial, escreve a partir de um jogo gráfico que revela a preservação da estrutura textual adquirida em práticas de letramento anteriores.

Dessa forma, esse texto pode ser compreendido como "manifestação de um impacto no processo de captura pela linguagem" (ARANTES, 2009, p. 2), em razão de que esse movimento de escritura coloca em evidência a "prisão" do sujeito a uma falta ou falha da linguagem escrita, mas que ao mesmo tempo assinala sua presença na linguagem, visto que a afasia, conforme Macedo (2005), diz respeito à alteração da linguagem.

É importante ressaltar que nesse primeiro texto o papel de intérprete assumido pelo outro (terapeuta) foi fundamental para que o sujeito seguisse o processo de recuperação do movimento de escrita, visto que a capacidade de produzir e entender a linguagem escrita, mais do que identificada e nomeada, precisa ser compartilhada, segundo Macedo (2010, p. 240), com outro que ajude o sujeito na produção final desejada.

Nessa perspectiva, as condições de interação no processo de recuperação da escrita e as práticas de letramento do sujeito são fundamentais para que o movimento de escritura seja restabelecido, como veremos nos próximos textos.

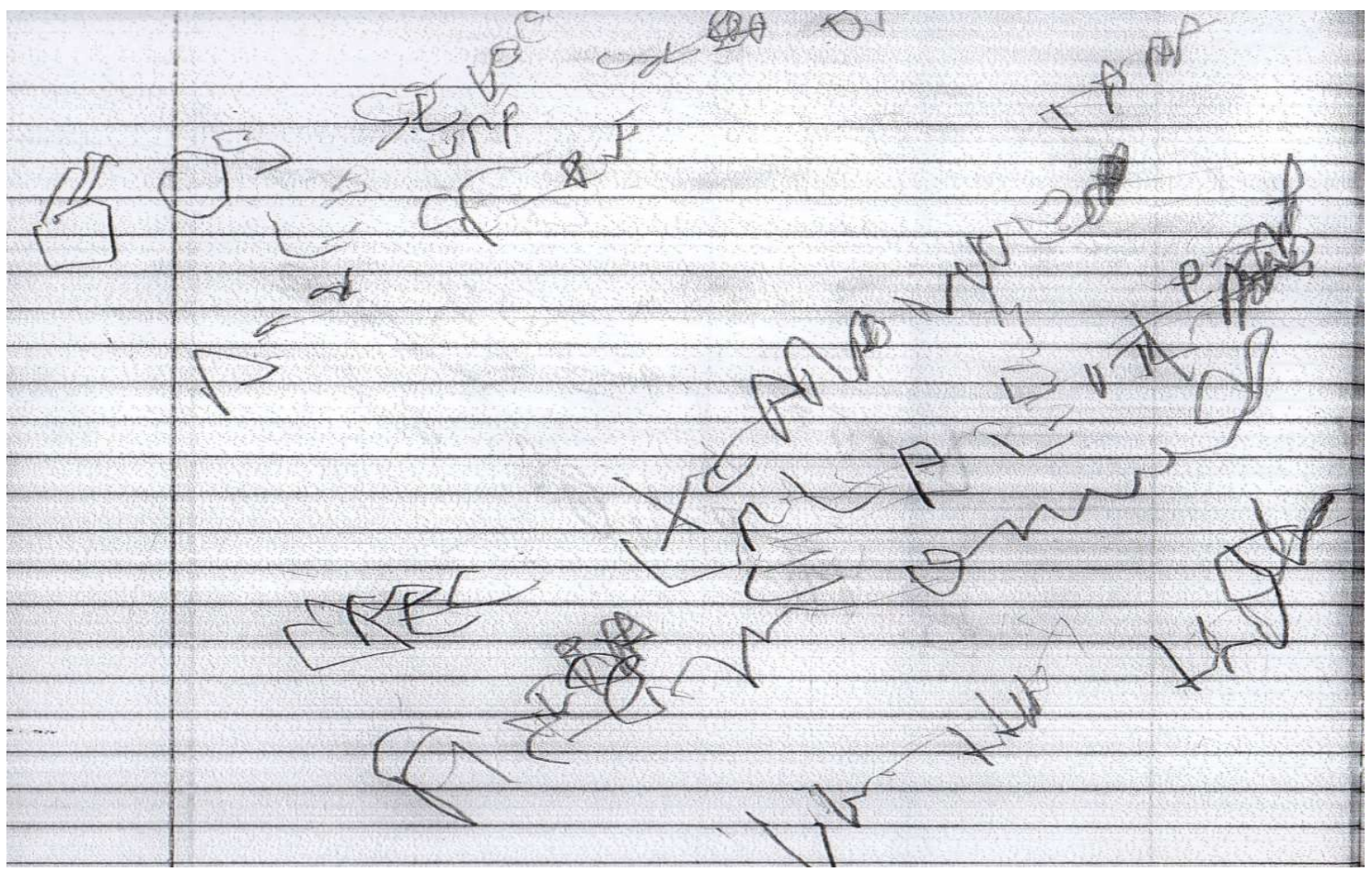

Texto 2: Sem data 
Considerando que, na escrita inicial, as primeiras letras que aparecem são as que representam o nome próprio, segundo Borges (2006), por uma questão de assinatura e de inscrição do sujeito na escrita, observamos nesse texto que, semelhante à criança em fase de aquisição de escrita, o sujeito escreve letras que remetem à composição de seu nome $(\mathrm{O}, \mathrm{S}, \mathrm{E}, \mathrm{A}, \mathrm{M}, \mathrm{L}, \mathrm{U}$ e V $)$.

Analisando a escrita da criança, Saleh (2008) diz que quando os traçados das letras ou mesmo de uma única letra do nome da criança aparecem em seus textos, não é apenas a semelhança do traçado que está nessa escrita, mas toda a história dos textos que o adulto significou para ela.

Com base nisso, podemos supor que, no caso do sujeito afásico, a emergência das letras de seu nome retrata a significação dada pelo outro aos seus textos, assim como os indícios de preservação de seu letramento, tendo em vista que, diferente da criança em fase de aquisição, o afásico é um sujeito constituído que, devido ao episódio neurológico, está preso a uma falta ou falha da linguagem, mas busca recuperar a escritura de textos da língua constituída, pois o aparecimento das letras do seu nome "resulta na realização de uma marca em que o sujeito está investido" (BOSCO, 2009, p. 20).

Dessa forma, observa-se que, durante o processo de recomposição da escrita, o afásico, tal como a criança, necessita do outro que o coloque em contato com textos, em razão de que o sujeito no trajeto inicial de recuperação da linguagem alienado aos textos do outro (não afásico) tende a imitá-los em sua escrita. 


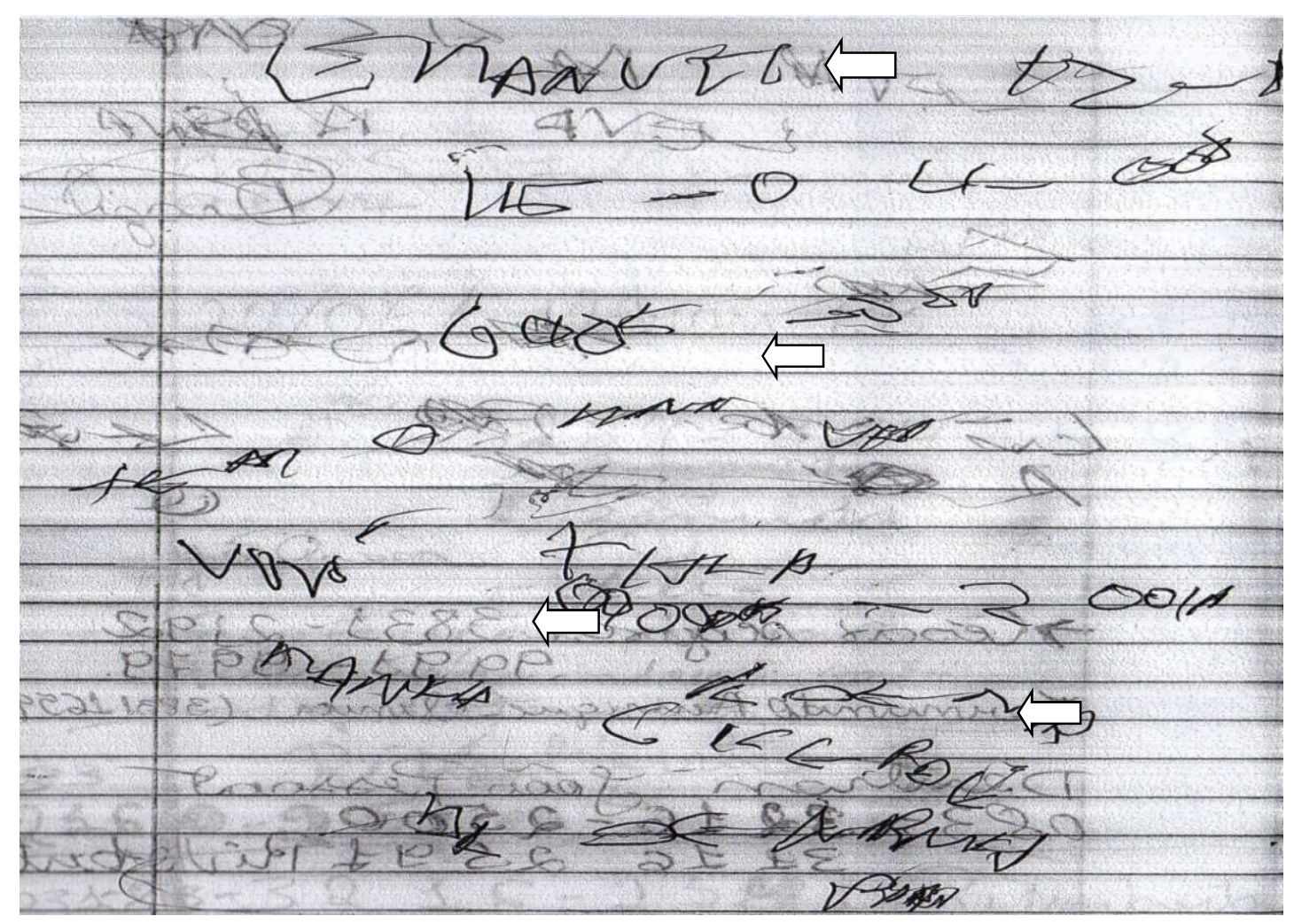

Texto 3: Sem data

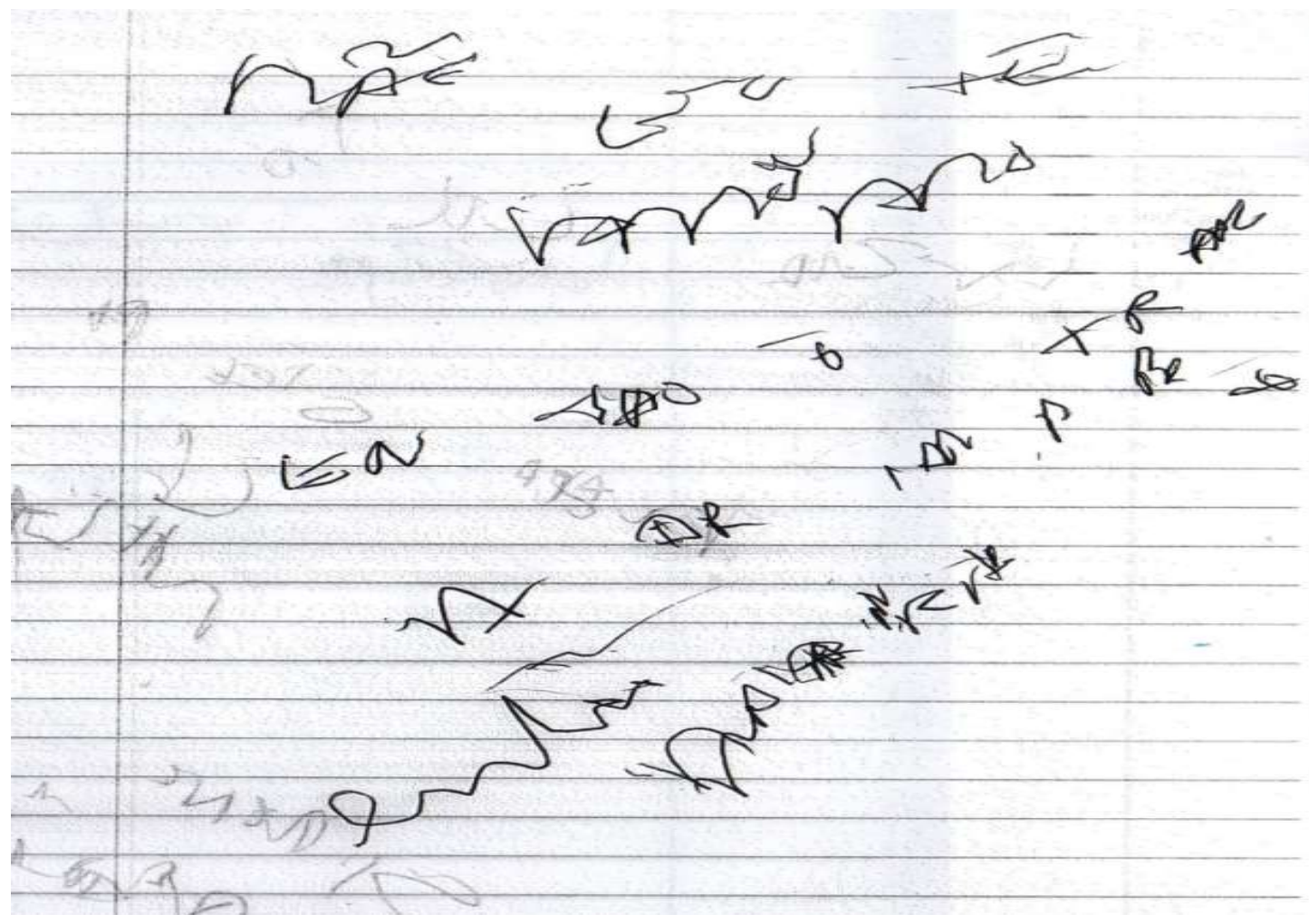

Texto 4: Sem data 
No período de escrita desses textos, ocorrido depois da alta hospitalar, o sujeito orientado a dar continuidade aos tratamentos de fisioterapia e fonoaudiologia, também realizava exercícios complementares de fala e escrita orientados e acompanhados por sua mãe.

Nesses exercícios, a mãe solicitava que o sujeito escrevesse textos relacionados aos acontecimentos de seu cotidiano como os nomes de familiares que o acompanhavam diariamente, listas de compras e resolução de problemas matemáticos. Em dois desses momentos de interação, solicitado a escrever nomes de pessoas importantes para o sujeito, observa-se no Texto 3 que, entre alguns traços incompreensíveis de letras, aparece o nome do sujeito (Emanuel), seguido pela forma como ele chamava sua noiva (Ana) e das palavras "vovó", "tia", "mainha" e "Cícera" (nome da mãe). No Texto 4, pode-se ler a frase "mãe eu te amo" e ainda a palavra "Adriana" (nome da noiva do sujeito), além de algumas letras do nome do sujeito e outros traços enigmáticos ${ }^{12}$.

A articulação das letras compondo palavras e frases, nesses textos, encaminha-nos à afirmação de Borges de que as unidades articuladas "emergem sob efeito da relação entre múltiplas impressões advindas de textos (o objeto de conhecimento) e dos feixes de representações já inscritos na memória” (BORGES, 2006, p. 151, grifo da autora).

Com isso, presume-se que o sujeito afásico, afetado pelo outro (semelhante) e capturado pela linguagem, escreve textos que se assemelham às produções escritas iniciais da criança, podendo esses textos também ser interpretados como decorrentes do movimento "da linguagem sobre a linguagem" (LEMOS, 1992, p. 132).

\footnotetext{
${ }^{12}$ Esse termo é usado no Interacionismo em Aquisição de Linguagem para fazer referência à natureza das falas sintomáticas e aos efeitos produzidos por elas, pois, de acordo com Arantes (2009, p. 2), "os sintomas na fala são produções enigmáticas não redutíveis a movimentos desajeitados do aparelho fonador". Diante disso, compreendemos que os grafismos na escrita do sujeito afásico em fase de (re) constituição da linguagem podem ser nomeados como "traços enigmáticos", em razão de que esses traços de escrita podem ser interpretados, na Afasia, parafraseando Fonseca (2006, p. 337), como o enigma de uma escrita desarranjada (ou ausente).
} 


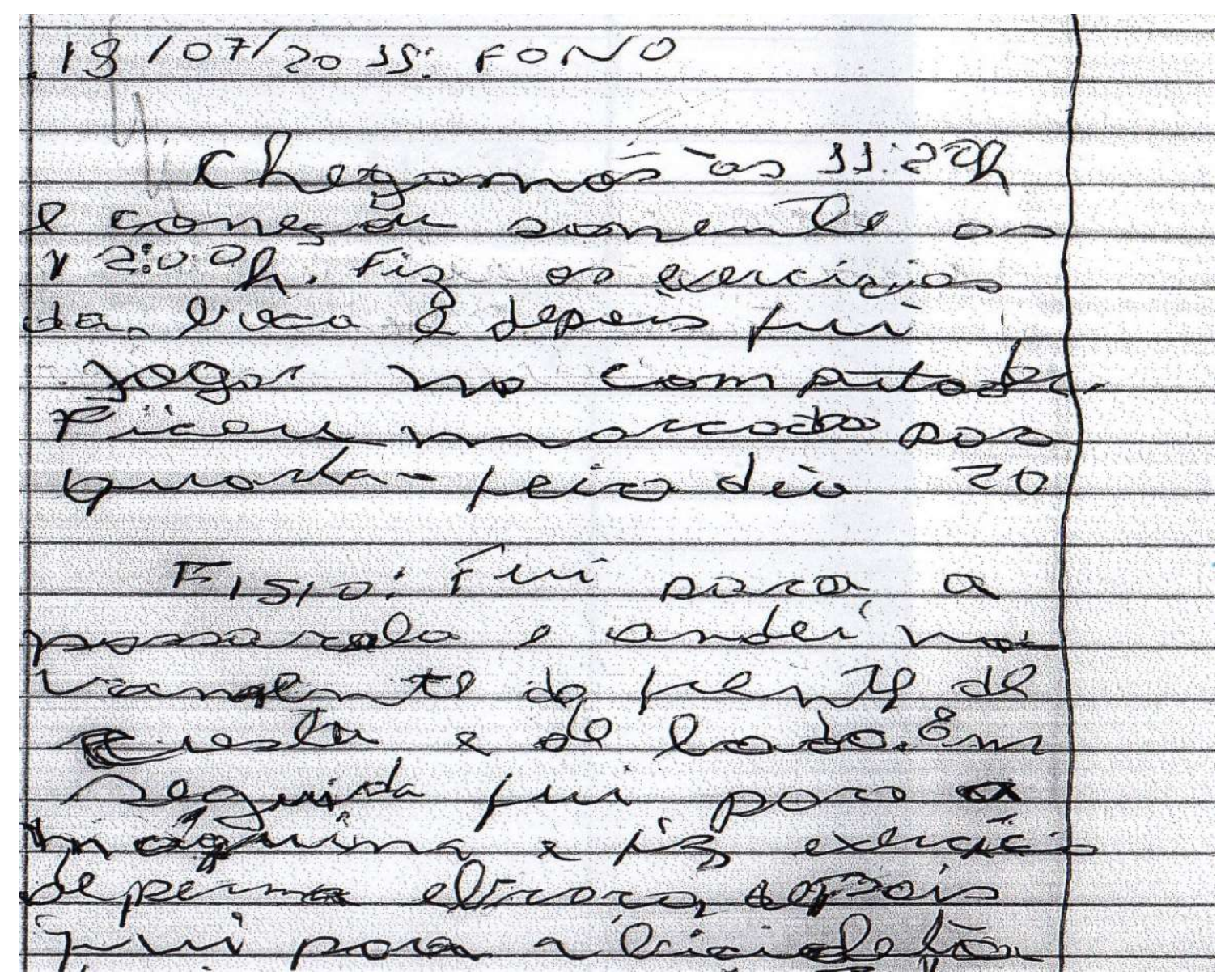

Texto 5: 18/07/2011

Escrito em 18/07/2011, cinco meses após o evento neurológico, esse texto aponta para a importância do contexto discursivo em que o sujeito está inserido, seja a criança em fase de aquisição ou o afásico em processo de recomposição da linguagem escrita. Isso porque a linguagem ou a limitação dela, no caso da afasia, "é uma questão essencialmente discursiva, não redutível, isoladamente, aos recursos da língua, isto é, à língua" (MACEDO, 2005, p. 12).

Com base nessa perspectiva, a descrição feita pelo sujeito nesse texto sobre as atividades realizadas nas sessões de fonoaudiologia e fisioterapia evidencia que "os processos de (re) construção da leitura e da escrita também se dão numa sucessão de momentos discursivos, de interlocução e interação entre o sujeito, seus interlocutores, a linguagem e o mundo social" (SANTANA, 2002, p. 18), pois o sujeito afásico apesar da alteração e limitação de linguagem está cercado de atividades linguageiras em seu cotidiano. O que requer a proposição de atividades eficientes de escrita como a produção 
de textos o mais próximo possível, conforme Santana (2002, p. 63), de situações efetivas de uso da linguagem.

Nesse entendimento, observa-se que a introdução sistemática de atividades de escrita, que envolveram situações da rotina de recuperação do sujeito, ocorreu de maneira semelhante à relação criança-adulto, no Interacionismo em Aquisição de Linguagem, visto que, nessa proposta teórica, o adulto é o outro que conduz a criança à linguagem e a interpreta por meio da língua. Com isso, esse texto desvela que o processo de recomposição da linguagem ocorre pautado pela relação do sujeito com o outro e com a língua.

No que diz respeito ao papel do outro no processo de escritura desse texto, podese compreender que a atuação desse outro, nesse caso, a mãe do sujeito, foi a de colaborador, visto que a proposição de uma escrita situada, segundo Macedo (2005), caracteriza a interação como uma relação de colaboração.

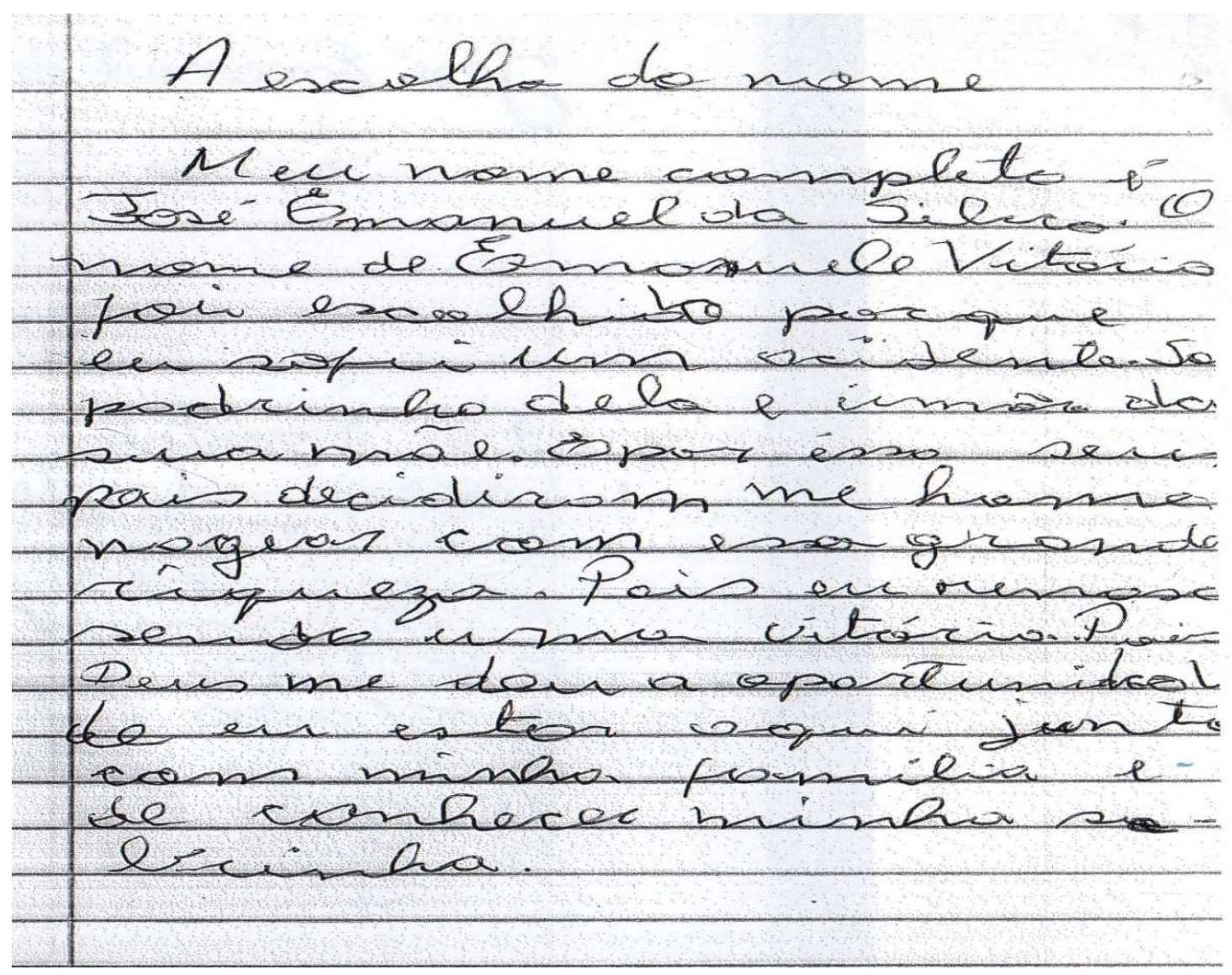

Texto 6: 20/08/2011 
Nesse texto, escrito em 20/08/2011, diferente do texto anterior em que as atividades realizadas pelo sujeito foram descritas de forma breve e pontuada, nota-se uma escrita textualmente organizada, assinalando o completo restabelecimento da linguagem escrita do sujeito, que, solicitado pela mãe a escrever algo sobre sua história, optou por narrar um dos acontecimentos marcantes de sua vida.

Na redação, intitulada "A escolha do nome”, o sujeito narra a escolha do nome de sua sobrinha, iniciando o texto com a apresentação de seu nome completo e fazendo referência ao acidente sofrido e seu "renascimento", que para o sujeito foi uma "vitória".

O surpreendente dessa escrita não é apenas o fato de se configurar como um texto da língua escrita constituída, mas principalmente de apresentar elementos de coesão referencial, como os pronomes possessivos "sua" e "seus" (linha 7), além da presença das conjunções explicativas "porque" (linha 4) e "pois" (linhas 10 e 12), o que nos encaminha à afirmação de Jakobson de que "a pesquisa sobre a ordem das aquisições e das perdas e sobre as leis gerais de implicação não pode ser limitada ao sistema fonológico, mas de estender-se também ao sistema gramatical” (JAKOBSON, 2008, p. 36).

No entanto, como não é nosso propósito tratar sobre questões de linguística textual na escrita do sujeito, achamos por bem não adentrarmos nesse campo, mas chamar atenção para o fato de que, no processo de recuperação da escrita, é preciso considerar as práticas de letramento do sujeito afásico "para que se possa configurar a dificuldade apresentada como um agramatismo, e não, por exemplo, um desconhecimento e uma falta de uso anterior ao episódio neurológico, das práticas de e com a linguagem escrita" (MACEDO, 2010, p. 222).

No caso aqui apresentado, por se tratar de um sujeito cujas práticas de leitura e escrita eram frequentes antes do dano neurológico, compreende-se que, no percurso de recomposição da escrita, a produção de textos que representavam situações de seu cotidiano foi fundamental para a mudança de sua condição de sujeito com limitação de linguagem para a de sujeito-escrevente.

Diante disso, é possível compreender que buscar outro entendimento de escrita na afasia em uma proposta não representacionalista, nem reduzida a exercícios de metalinguagem "abre caminho para a vertente interacionista em Aquisição da Linguagem" (LEITE, 2006, p. 271), pois o sujeito em estado de afasia é, do mesmo modo que a criança em fase de aquisição da linguagem, “capturado por le langage, atravessado 
e significado pela parole do outro, matriz de sua identificação como semelhante - [...] e como dessemelhante, referido a uma subjetividade figurada como individual" (LEMOS, 2006, p. 27) e que por meio da interação com o outro pode ser reconduzido ao movimento linguístico-discursivo da escrita.

\section{Considerações finais}

Objetivando uma aproximação ao percurso de reconstituição da escrita de um sujeito afásico, cuja linguagem foi severamente perturbada, buscamos através de textos escritos de modo longitudinal e cedidos após a recuperação do sujeito, compreender o processo de recomposição da linguagem escrita, a partir das reflexões teóricas oferecidas pela Neurolinguística e pelo Interacionismo em Aquisição de Linguagem.

Os resultados apontaram que o sujeito, na fase inicial do percurso, escrevia textos incompreensíveis para outros leitores, mas que comportavam significados para ele. Em outro momento do percurso, quando as letras da língua constituída começaram a aparecer na escrita do sujeito, observou-se a emergência das letras que compõem seu nome e que, embora não dispostas linearmente no papel, aparecem escritas lado a lado, desvelando a preservação da estrutura textual adquirida pelo sujeito nas práticas de letramento anteriores ao trauma.

Quando solicitado a produzir textos relacionados aos acontecimentos de seu cotidiano, observou-se que entre traços enigmáticos aparecem letras do nome do sujeito e as formas como ele se referia às pessoas próximas (Ana, vovó, tia, mainha e Cícera), além da escrita de pequenas frases, indicando que o afásico afetado pelo outro e capturado pela linguagem, em determinada fase do trajeto de recomposição da escrita, escrevia textos que indicavam a preservação de seu letramento.

Em outro momento, solicitado a descrever atividades do cotidiano de recuperação, observou-se que o sujeito já escrevia textos claros, corretos e coerentes, inclusive com a presença de elementos de coesão referencial, ratificando a afirmação de Santana (2002) de que atividades de produção de textos o mais próximo possível de situações efetivas de uso são mais eficientes para a recuperação da escrita na afasia, uma vez que o afásico, apesar da limitação de linguagem, está cercado de situações linguageiras.

Nesse cotidiano linguageiro, a interação com o outro e a atuação deste como intérprete e como o que conduz o sujeito à escrita foram fundamentais para o processo de 
reconstituição da escrita do afásico que, semelhante à criança em fase de aquisição de linguagem, passou pela mudança de posição, cujos polos, conforme proposto por Lemos (2002), são o outro, a língua e o próprio sujeito.

Diante disso, observou-se que a trajetória de recuperação desse sujeito e sua mudança de sujeito com limitação de linguagem para a de escrevente foi marcada pela dimensão linguageira da interação, em razão de que o outro (terapeuta e mãe) se apresentou como portador do texto-discurso que conduziu o sujeito à escrita por meio de atividades que envolviam situações reais de comunicação, (re) inserindo-o, dessa maneira, no funcionamento da linguagem escrita.

Para finalizar, reconhecemos que a pesquisa sobre o percurso de reconstituição da escrita na afasia, a partir do Interacionismo em Aquisição de Linguagem, não se esgota aqui, pois, ao partirmos do pressuposto de que o contato com atividades de escrita mediadas pelo outro em situações reais de comunicação favorece a recomposição da escrita do sujeito afásico, verificamos que a trajetória de recuperação da escrita na afasia merece uma maior discussão pela linguística.

CARVALHO, Magda Wacemberg Pereira Lima; AZEVEDO, Nadia Pereira da Silva Gonçalves de. The writing in aphasia: from the loss to the reconstruction of the language. Revista do Gel, v. 14, n. 2, p. 27-52, 2017.

Abstract: Considering that, in aphasia, the symptomatic situation involving the language is marked by the "insistence/persistence of a difference" (LIER-DE VITTO, 2006, p. 186, italics by the author), this study aims to understand aspects of the reconstitution process of a person's writing within a state of aphasia, whose language was seriously disrupted. From this purpose, we have constituted a corpus of analysis formed by six texts written by the subject at different moments of his recovery. The theoretical support fundamentally comes from experts on Aphasia, Neurolinguistics, Language Acquisition and Language Pathologies, among those they are Freud (1977 [1891], 2013); Jakobson (2008 [1954]); Morato (2010, 2012); Santana (2002); Macedo (2005, 2010); Lemos (1992, 1998, 2002, 2006); Lier-De Vitto (2006); Arantes (2006, 2009) e Borges (2006). The results showed that the movement of (re)constructing the person's writing was marked by the interaction with other people (a therapist or a family member) who, as a holder of the text-speech, led the subject throughout activities involving everyday situations, thus they were able to (re)introduce him to the linguistic-discursive operation.

Keywords: Language. Aphasia. Writting. 
Submetido em: 21/08/2016.

Aceito em: 07/01/2017.

\section{Referências}

ARANTES, L. Impasses na distinção entre produções desviantes sintomáticas e não sintomáticas. In: LIER-DE VITTO, M. F.; ARANTES, L. (Org.). Aquisição, patologias e clínica de linguagem. São Paulo: EDUC, FAPESP, 2006. p. 219-226.

. Diagnóstico de linguagem: sobre os efeitos das falas sintomáticas. In:

Simpósio Nacional de Letras e Linguística, Anais do SILEL. v. 1, n. 1, p. 1-5.

Uberlândia: EDUFU, 2009. Disponível em:

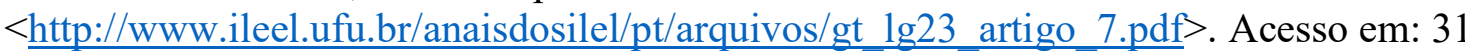
jul. 2016.

BAKHTIN, M. Os gêneros do discurso. In: Estética da criação verbal. 4. ed. São Paulo: Martins Fontes, 2003.

BORGES, S. X. de A. A aquisição da escrita como processo linguístico. In: LIERDEVITO, M. F.; ARANTES, L. (Org.). Aquisição, patologias e clínica da linguagem. São Paulo: EDUC, FAPESP, 2006. p. 149-159.

BOSCO, Z. R. A Errância da Letra: O nome próprio na escrita da criança. Campinas: Pontes Editores, 2009.

CANGUILHEM, G. O normal e o patológico. 6. ed. rev. Rio de Janeiro: Forense Universitária, 2009 [1966].

FONSECA, S. C. da. O estatuto da entrevista no processo diagnóstico da afasia. In: LIER-DE VITTO, M. F.; ARANTES, L. (Org.). Aquisição, patologias e clínica de linguagem. São Paulo: EDUC, FAPESP, 2006. p. 331-339.

FREUD, S. A interpretação das afasias: um estudo crítico. São Paulo: Edições 70, Persona, 1977 [1891].

Sobre a concepção das afasias: um estudo crítico. Belo Horizonte: Autêntica Editora, 2013 [1891].

GOODE, W. L.; HATT, P. K. Métodos em pesquisa social. 5. ed. São Paulo:

Companhia Editora Nacional, 1979.

JAKOBSON, R. Linguística e Comunicação. 21. ed. São Paulo: Editora Cultrix, 2008 [1954].

KAUARK, F. da S.; MANHÃES, F. C.; MEDEIROS, C. H. Metodologia da pesquisa: guia prático. Itabuna: Via Litterarum, 2010. 
LACAN, J. O Seminário, livro 11. Os quatro conceitos fundamentais da psicanálise. 2. ed. Rio de Janeiro: Zahar, 2008 [1964].

LEITE, L. O sintoma na escrita e sua ilusória transparência. In: LIER-DE VITTO, M. F.; ARANTES, L. (Org.). Aquisição, patologias e clínica de linguagem. São Paulo: EDUC, FAPESP, 2006. p. 269-276.

LEMOS, C. T. G. de. Los processos metafóricos y metonímicos como mecanismos de cambio. Substratum/Artes Médicas, v. 1, n. 1, p. 121-136, 1992.

Sobre a aquisição da escrita: algumas questões. In: ROJO, R. Alfabetização e letramento: perspectivas linguísticas. Campinas: Mercado de Letras, 1998. p. 8-18.

Das Vicissitudes da Fala da Criança e sua Investigação. Cadernos de Estudos Linguísticos, Campinas: IEL/Unicamp, n. 42, p. 41-69, 2002.

. Uma crítica (radical) à noção de desenvolvimento na Aquisição da Linguagem. In: LIER-DE VITTO, M. F.; ARANTES, L. (Org.). Aquisição, patologias e clínica de linguagem. São Paulo: EDUC, FAPESP, 2006. p. 21-32.

LIER-DE VITTO, M. F. Patologias da linguagem: sobre as "vicissitudes de falas sintomáticas". In: LIER-DE VITTO, M. F.; ARANTES, L. (Org.). Aquisição, patologias e clínica de linguagem. São Paulo: EDUC, FAPESP, 2006. p. 183-200.

LIER-DE VITTO, M. F.; CARVALHO, G. M. O Interacionismo: uma teorização sobre a aquisição da linguagem. In: QUADROS, R. M. de; FINGER, I. (Org.). Teorias de aquisição da linguagem. Santa Catarina: Editora da UFSC, 2008. p. 115-146.

MACEDO, H. de O. O Processo de refacção textual na linguagem escrita de sujeitos afásicos. 2005. $227 \mathrm{f}$. Tese (Doutorado em Linguística) - Instituto de Estudos da Linguagem, Universidade Estadual de Campinas, Campinas, 2005.

A semiologia da escrita nas afasias. In: MORATO, E. M. (Org.). A Semiologia das afasias: perspectivas linguísticas. São Paulo: Cortez, 2010. p. 214-242.

MORATO, E. M. As querelas da semiologia das afasias. In: (Org.). A semiologia das afasias: perspectivas linguísticas. São Paulo: Cortez, 2010. p. 23-47.

Neurolinguística. In: MUSSALIN, F.; BENTES, A. C. (Org.). Introdução à linguística: domínios e fronteiras. 8. ed. São Paulo: Cortez, 2012. p. 167-200.

OLIVEIRA, M. M. Como fazer pesquisa qualitativa. 4. ed. Petrópolis: Vozes, 2012.

POMMIER, G. A história da escrita e a aprendizagem de cada criança. In: LIER-DE VITTO, M. F.; ARANTES, L. (Org.). Faces da escrita: linguagem, clínica, escola. Campinas: Mercado de Letras, 2011. p. 17-31. 
SALEH, P. B. de Oliveira. Aquisição de linguagem e ensino de língua materna: um lugar para a subjetividade. Revista Uniletras, Ponta Grossa, v. 30, n. 1, p. 157-172, jan./jun. 2008. Disponível em:

$<$ http://www.revistas2.uepg.br/index.php/uniletras/article/view/192/190>. Acesso em: 10 jul. 2016.

SANTANA, A. P. Escrita e Afasia: o lugar da linguagem escrita na Afasiologia. São Paulo: Plexus Editora, 2002.

SAUSSURE, F. de. Curso de Linguística Geral. 27. ed. São Paulo: Cultrix, 2006 [1916].

VIEIRA, C. H. Sobre as afasias: o doente e a doença. In: LIER-DE VITTO, M. F.; ARANTES, L. (Org.). Aquisição, patologias e clínica de linguagem. São Paulo: EDUC, FAPESP, 2006. p. 235-246. 